2. Автоматизированное рабочее место (АРМ) сейсмолога // Федеральное государственное бюджетное учреждение науки Федеральный исследовательский центр Единая геофизическая служба PAH: сайт. - URL: http://www.ceme.gsras.ru/new/soft/wsg arm.htm (Дата обращения: 22.03.2021).

3. Маловичко А.А., Маловичко Д.А., Дягилев Р.А., Верхоланцев Ф.Г., Голубева И.В., Верхоланцев А.В. Пермский край 1999-2005 гг. // Землетрясения Северной Евразии, 2005 год. - Обнинск: ГС РАН, 2011. - C. 269-289.

4. Waldhauser F. hypoDD -- A Program to Compute Double-Difference Hypocenter Locations / U.S. Geol. Survey. - 2006. - URL: https://www.ldeo.columbia.edu/ felixw/papers/ Waldhauser_OFR2001.pdf. (Дата обращения: 15.01.2021).

5. EMAG2: Earth Magnetic Anomaly Grid (2-arc-minute resolution. - Текст электронный. - URL: http://geomag.org/models/emag2.html, свободный (дата обращения 15.01.2021).

6. Kanamori H., Mori J., Hauksson E., Heaton T.H., Hutton L.K., Jones L.M. Determination of Earthquake Energy-Release and M(L) using Terrascope // Bulletin of the seismological Society of America. - 1993. V. 83, № 2. - P. 330-346.

\title{
ОПТИМАЛЬНЫЕ ПУТИ ПОДАВЛЕНИЯ БОКОВЫХ ВОЛН-ПОМЕХ ПРИ ЦИФРОВОЙ ОБРАБОТКЕ ШАХТНЫХ СЕЙСМОАКУСТИЧЕСКИХ ДАННЫХ
}

\author{
В.Ю. Бобров \\ Горный институт УрО РАН, г. Пермь
}

\begin{abstract}
Аннотация: Рассмотрены способы подавления неспецифических волн-помех, являющихся отличительной особенностью шахтной сейсморазведки. Показаны результаты применения f-k фильтрации по разным сортировкам сейсмограмм при обработке продольных волн.

Ключевые слова: шахтная сейсморазведка, цифровая обработка данных, продольные волны, сортировка полевых сейсмограмм.
\end{abstract}

Особенностью сейсмоакустических наблюдений во внутренних точках среды (горных выработках) является совместная регистрация волн продольного (Р) и поперечного (S) типов. Применяемые в настоящее время на калийных рудниках многоволновые сейсмоакустические исследования [1] построены на разделении разнотипных волновых полей процедурами специальной цифровой обработки. Эффективному выделению волн того или иного типа способствуют их существенные различия по кажущимся скоростям и частотам [2]. Поэтому основными процедурами в цифровой обработке являются пространственные фильтры. При выделении отражённых Р-волн поперечные являются помехами, и, наоборот, при выделении отражённых S-волн подавляются продольные.

Цель цифровой обработки - выделение целевых сейсмических сигналов, несущих в себе информацию о особенностях строения геологической среды [3]. Применительно к шахтным сейсморазведочным наблюдениям эффективное выделение информативных сигналов осложнено наличием неспецифических регулярных волн-помех. Наиболее интенсивные из них - «боковые» отражения прямой волны от сбоек, подрезок и других горнотехнических элементов, распространяющиеся вдоль штрека по приконтурной части породного массива. На сейсмограммах годографы «боковых» отражённых волн представляют собой линии с началом в точке подхода прямой волны до отражателя на профиле (рис. 1) и постоянным приращением времени регистрации от трассы к трассе в соответствии со скоростью распространения волн вдоль штрека. 


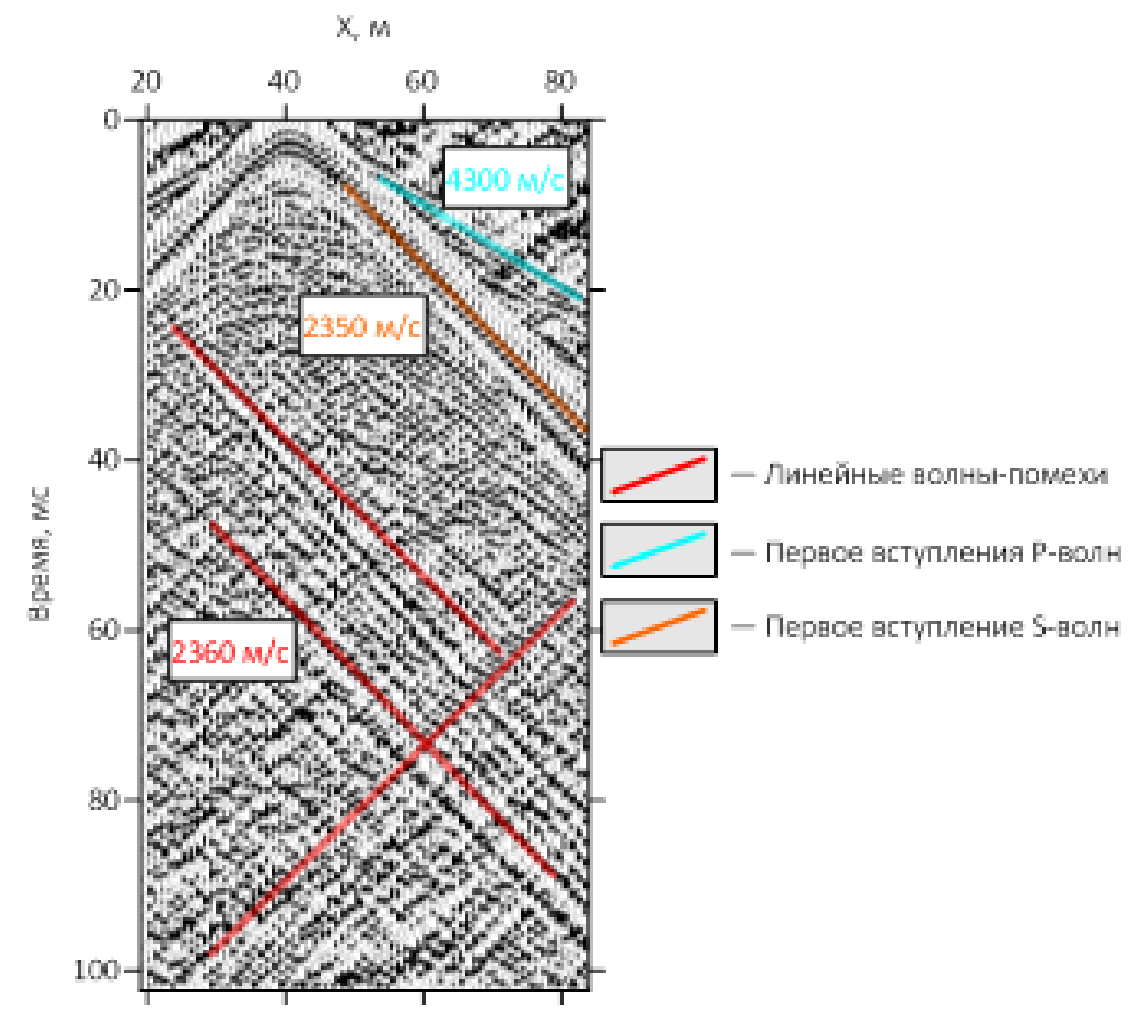

Рис. 1. Сейсмограмма ОПВ, полученная в шахтных условиях, с примененной минимальной обработкой (регулировка амплитуд, полосовая фильтрация)

В силу особенностей возбуждения поля упругих волн от ударного источника в горных выработках, основной вклад в формирование данных волн-помех вносят прямые поперечные волны и следующие за ними поверхностные. Кажущаяся скорость соответствует скорости распространения поперечных волн вдоль линии наблюдения (штрека) $-\mathrm{V}_{\mathrm{S}}=$ от 2300 до $2600 \mathrm{~m} / \mathrm{c}(750-850$ дс/100 трасс). При этом относительно приёмной линии она может быть как положительной, так и отрицательной. Т.е. на малых удалениях ПВ-ПП время регистрации больше, чем на больших. Это накладывает определённые трудности в подавлении «боковых» волн-помех традиционными процедурами веерной фильтрации.

Так, если при цифровой обработке на выделение Р-волн подобные помехи весьма эффективно купируются на сейсмограммах ОПВ посредством f-k фильтра, построенного для подавления узкой (шириной 15 Гц) линейной (750 дс / 100 тр) области $[4,5]$ (рис. 2аб), не затрагивая полезную, в данном случае продольную составляющую сигнала, то для выделения отражённых от границ S-волн данный подход может вносить искажения в конечный результат цифровой обработки, поскольку кинематика целевых S-волн в области больших удалений близка к кинематике линейных «боковых» помех. Отражённые целевые сигналы S-волн на больших удалениях, где наиболее эффективно их разделение с Р-волнами, могут быть утеряны.

Существует возможность частично избавиться от подобных помех путем ввода кинематических поправок со скоростным законом для S-волн с последующим применением линейного f-k фильтра (рис. 2авг). При данной последовательности удается сохранить отраженные S-волны, подавив часть линейных помех, не подвергшихся искривлению за счет ввода кинематики. Тем не менее, остаточные помехи с учетом их сильной интенсивности и схожести с S-волнами могут в дальнейшем повлиять на конечные результаты обработки. 


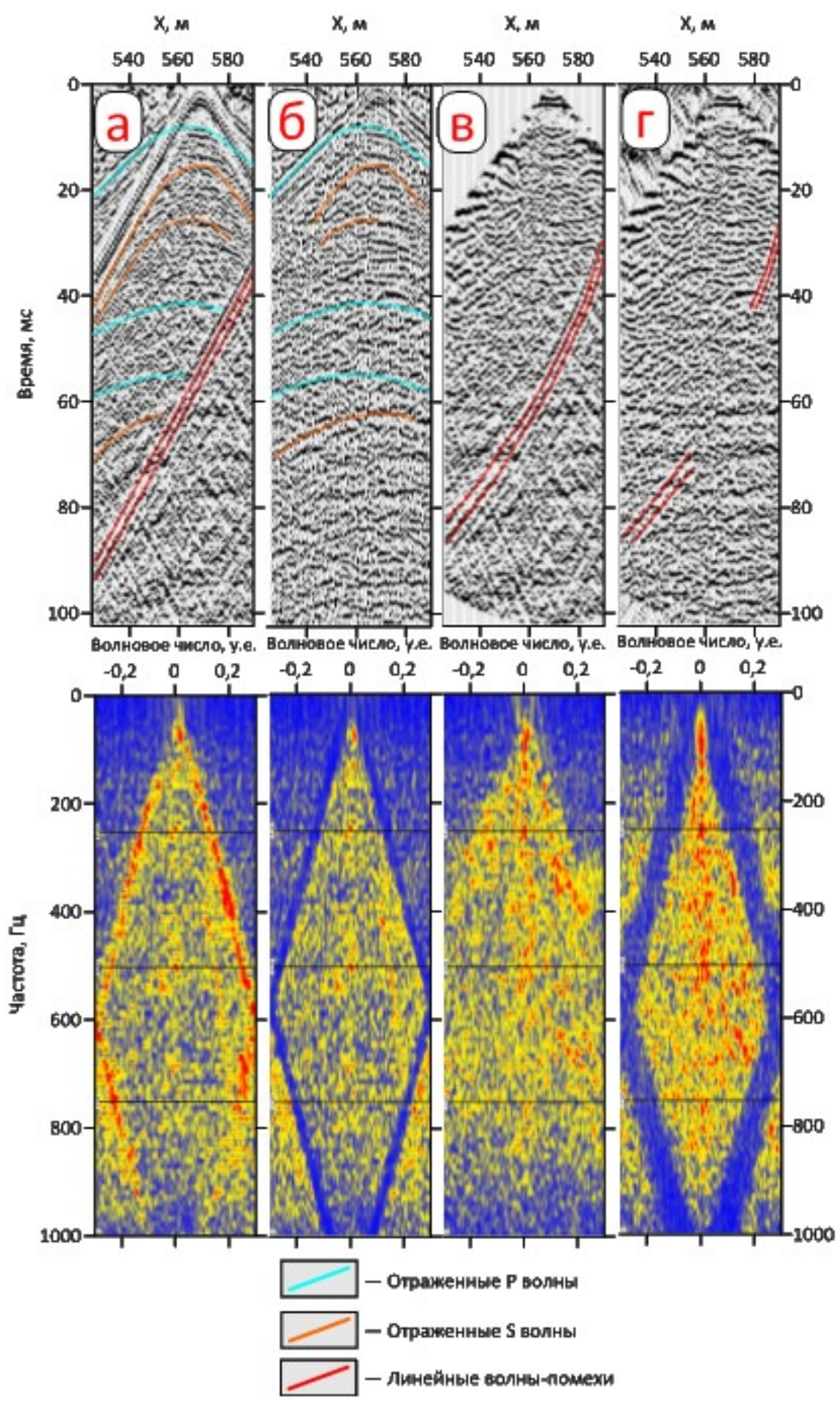

Рис. 2. Этапы обработки сейсмограммы ОПВ и еe f-k спектры.

a) исходная; б) после f-k фильтра по сортировке ОПВ до ввода кинематических поправок;

в) исходная, после ввода кинематических поправок без f-k фильтра;

в) после ввода кинематических поправок с последующей f-k фильтрацией по сортировке ОПВ

Как показывает практика [6, 7], в интерференционных системах наблюдений ОСТ искажения сейсмических регулярных волн, сформированных в данном случае от конструктивных особенностей выработок, можно учесть в различных выборках: общего пункта возбуждения (ОПВ), общего пункта приема (ОПП), общей средней точки (ОСТ) и общего удаления (ОУ) (рис. 3). Стоит заметить, что все сейсмограммы, кроме ОПВ, не регистрируются в полевых условиях, а получаются сортировкой трасс из последовательных сейсмограмм ОПВ [8]. 

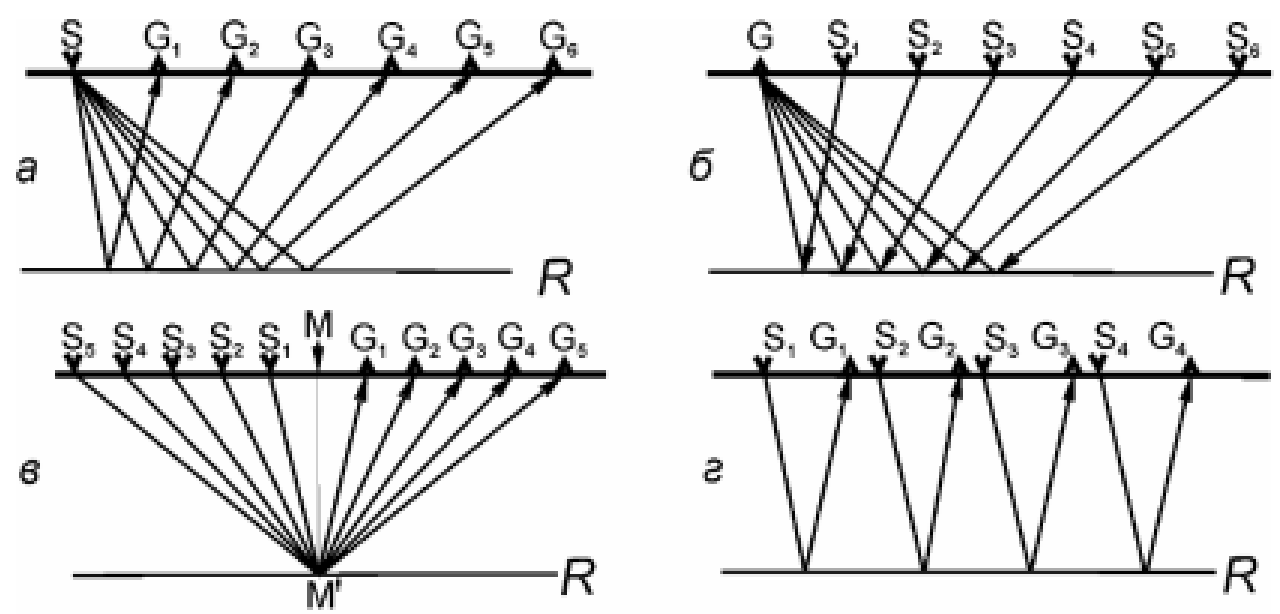

Рис. 3. Траектории отраженных лучей от границы $\mathrm{R}$ для сейсмограмм a) ОПВ, б) ОПП, в) ОСТ, где M' - общая глубинная точка, г) ОУ.

(S - пункт возбуждения, $\mathrm{G}$ - пункт приема)

Каждая выборка характеризуется своими особенностями представления регистрируемого волнового поля, например для ОПВ регулярность записи выдержана при вариациях формы возбуждаемого сигнала от пикета к пикету. Для ОПП это актуально для изменений условий приема. Выборка ОСТ слабо искажается наклонами горизонтов. ОУ нечувствительна к неточностям оценки скоростей и негиперболичности годографа. Сейсмограммы ОУ часто называют разрезами общих удалений с характерными для разрезов ОСТ особенностями сейсмической записи отражённых целевых сигналов с постоянным временем регистрации для каждой выборки ОУ. В этом случае пришедшие вдоль линии наблюдений сигналы, отражённые от сбоек и подрезок на профиле, будут иметь аналогичные с разрезами ОСТ пространственно-временные характеристики. Т.е. в виде осей синфазности с постоянным положительным или отрицательным приращением времени от трассы к трассе (рис. 4). В сортировке ОУ сигналы «боковых» волн-помех и целевых отраженных как S-, так и Р-волн характеризуются существенным различием наклонов их осей синфазности (кажущихся скоростей), что позволяет применить фильтрацию в $\mathrm{f}-\mathrm{k}$ области до ввода кинематических поправок, получив более корректное и эффективное подавление помех (рис 5).

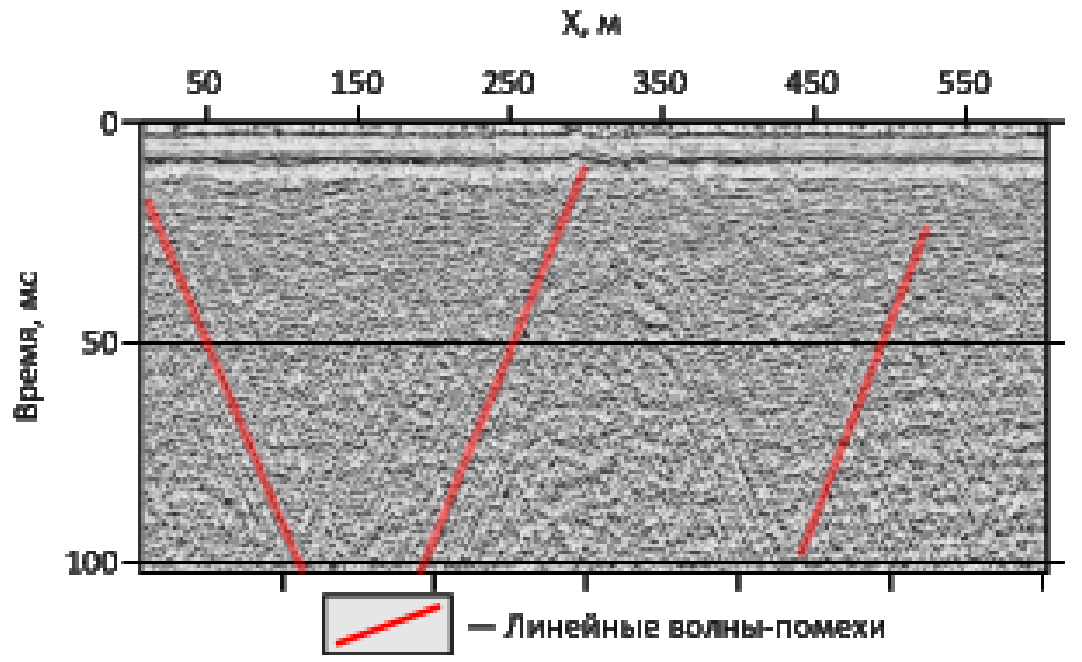

Рис. 4. Разрез ОУ с выборкой 28 метров 


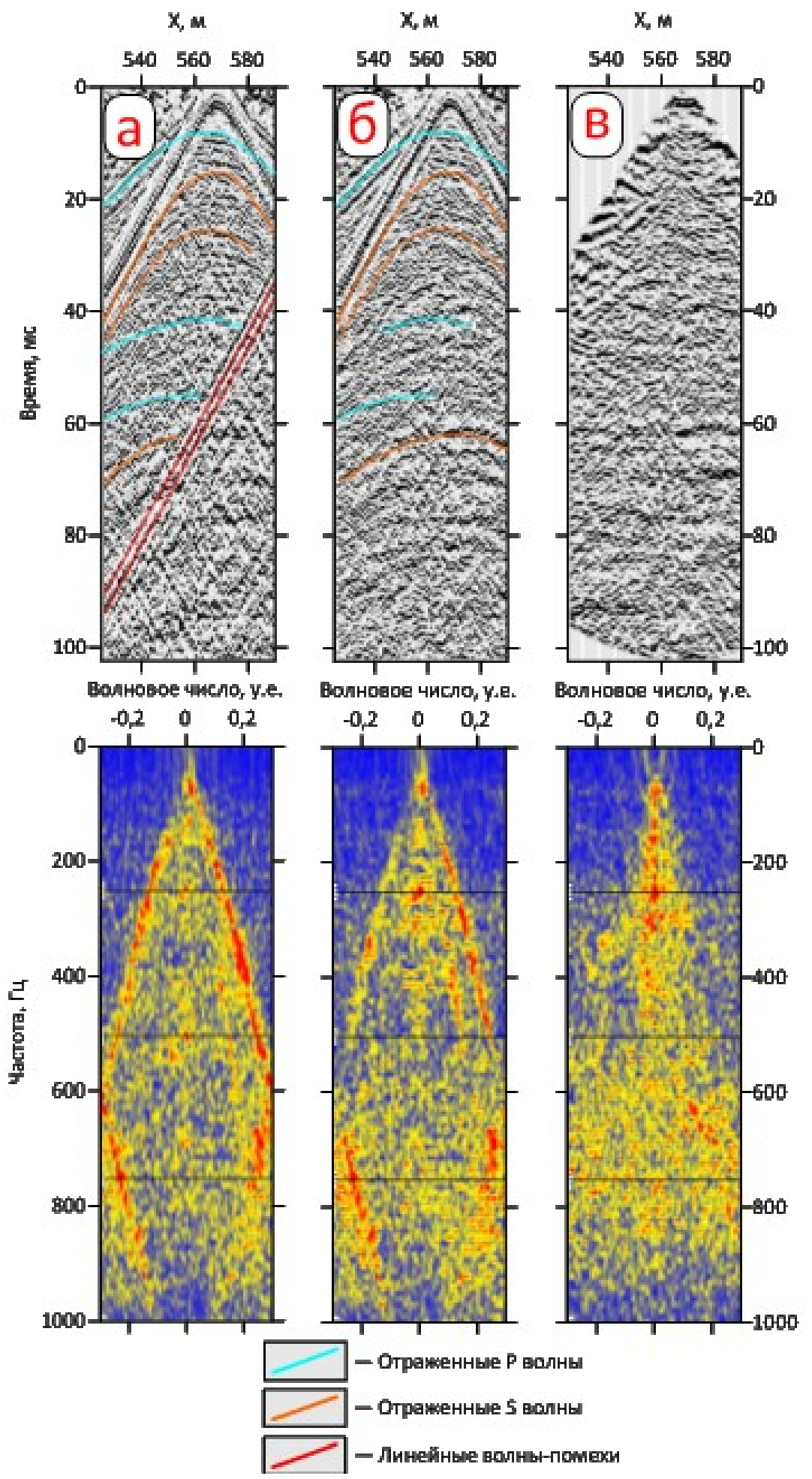

Рис. 5. Этапы обработки сейсмограмма ОПВ и еe f-k спектры.

a) исходная, б) после f-k фильтрации по сортировке ОУ, в) после ввода кинематических поправок

На участке с наиболее негативным влиянием геометрии выработок весьма заметна разница в подходах подавления линейных помех.

Можно отметить, что на глубинных разрезах, полученных без применения f-k фильтрации (рис. 6a) и c f-k фильтрацией по сейсмограммам с сортировкой ОПВ после ввода кинематических поправок (рис. 6б), в волновом поле более выражены регулярные помехи «боковых» отражённых волн, чем на разрезе, полученном с 
применением f-k фильтрации по сейсмограммам с сортировкой ОУ до ввода кинематики (рис. 6в).

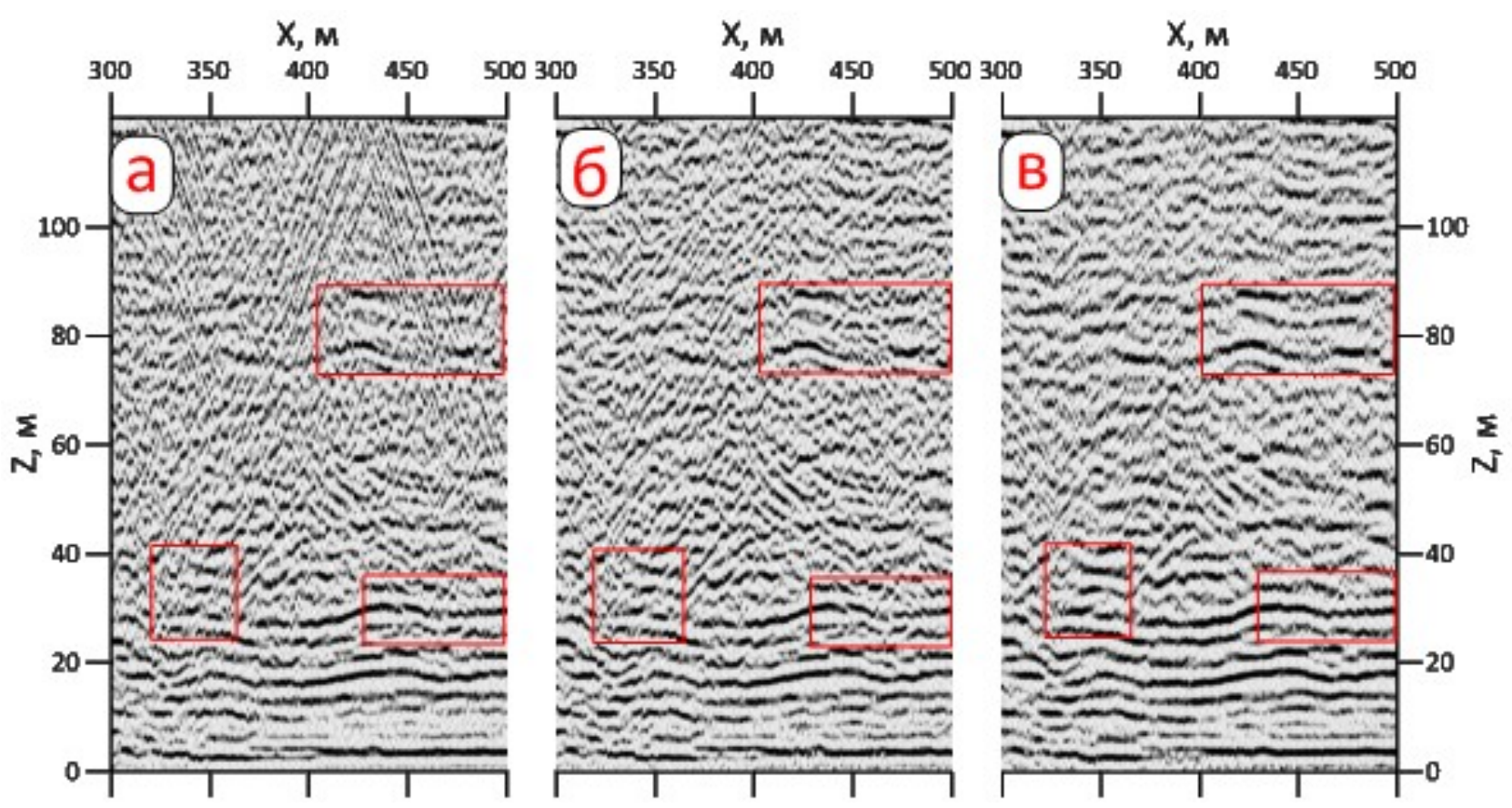

Рис. 6. Участок сейсмических глубинных разрезов для верхнего полупространства (ПК 300-500) для S-волн, по сейсмограммам:

a) без f-k фильтрации, б) c f-k фильтрацией по сейсмограммам с сортировкой ОПВ, в) c f-k фильтрацией по сейсмограммам с сортировкой ОУ.

Применена полосовая фильтрация $100-600$ Гц

Таким образом, основным выводом представленной работы является то, что при обработке шахтных сейсмоакустических данных с выделением поперечных волн наиболее корректное подавление «боковых» отражённых волн-помех достигается процедурой линейного f-k фильтра по выборкам общих удалений.

\section{Автор выражает благодарность А.И. Бабкину}

за идею, поддержку и содействие при выполнении данного исследования.

\section{Работа выполнена при поддержке РФФИ}

(грант № 20-45-596030 р_НОЦ_Пермский край)

\section{БИБЛИОГРАФИЧЕСКИЙ СПИСОК}

1. Инструкция по шахтной сейсморазведке (применительно к условиям Верхнекамского месторождения калийных солей): утв. ГИ УрО РАН, ПАО "Уралкалий" / ГИ УрО РАН; Санфиров И.А., Бабкин А.И. - Пермь, 2014. - 37 с.

2. Шерифф Р., Гелдарт Л. Сейсморазведка: В 2-х т. Т. 1. История и теория получения данных / Пер. с англ. Е.А. Ефимовой; под ред. А.В. Калинина - М.: Мир, 1987. - 447 с., ил.

3. Бондарев В.И. Сейсморазведка: учебник для вузов. - Екатеринбург: Изд-во УГГУ, 2007. - 690с.

4. Ярославцев А.Г., Клестов И.М. Особенности обработки данных шахтной сейсморазведки с целью разделения Р и S волн // Горное эхо. - 2020. - № 3 (80). - C. 101-106. - DOI: 10.7242/echo.2020.3.20.

5. Ярославцев А.Г., Фатькин К.Б. Шахтные сейсмоакустические исследования при контроле предохранительных целиков в калийных рудниках //. Инженерная и рудная геофизика - 2020: 16-я науч.практ. конф. и выставка, 14-18 сент. 2020. - Пермь, 2020. - DOI: 10.3997/2214-4609.202051043. 
6. Ференци В.Н, Елисеев В.Л, Табаков А.А, Огуенко Д.В, Степченков Ю.А., Мухин Д.А., Колосов А.С. Селекция волн в технологии сейсморазведки высокой четкости методом проектирования на области допустимых параметров. Материалы научно-практической конференции «Инновационные технологии и фундаментальная теория в сейсморазведке и сейсмологии», Москва, 2009, с. 11-18.

7. Ференци В.Н., Колосов А.С., Мухин А.А., Мухин Д.А. Вычитание частично нерегулярных волн в методе ОСТ по технологии Сейсморазведки Высокой Четкости // Galperin Readings 2011 - Innovative Technologies and fundamental Researches: 11 Annual International Conference \& Exhibitions, Oct 2011. Moscow, 2011. - Код 107625. - DOI: doi.org/10.3997/2214-4609.20144261.

8. Воскресенский Ю.Н. Построение сейсмических изображений: учеб. пособие для вузов. - М.: РГУ нефти и газа, 2006. - 116 с.

\title{
ВЛИЯНИЕ СОБСТВЕННЫХ (РЕЗОНАНСНЫХ) КОЛЕБАНИЙ ЗДАНИЯ НА РЕЗУЛЬТАТЫ НАТУРНЫХ ИЗМЕРЕНИЙ
}

\author{
А.В. Верхоланцев \\ Горный институт УрО РАН, г. Пермь
}

\begin{abstract}
Аннотация. В работе представлены результаты эксперимента по оценке пространственного распределения резонансных колебаний жилого 14-этажного дома. Работа имеет практический интерес для сейсмологов, ведущих наблюдения в непосредственной близости от зданий и сооружений, а также специалистов, занимающихся вопросами обследования и мониторинга их технического состояния.
\end{abstract}

Ключевые слова: сейсмическое воздействие, резонансы, собственная частота, резонансная частота, микросейсмический шум.

\section{Введение}

Наземные инженерные сооружения, испытывая различные нагрузки (ветровые и/или сейсмические воздействия), находятся в постоянном колебательном процессе. Основными количественными параметрами, характеризующими этот процесс, является собственная (резонансная) частота и логарифмический декремент затухания. Значения этих параметров зависят от многих факторов: это технология и глубина фундамента, размеры в плане, высота сооружения, тип и конструкция перекрытий, материалы несущих конструкций и заполнителя, уровень износа, состояние объекта и многое другое. Для выявления изменений напряженно деформированного состояния конструкций выполняют обследование и мониторинг технического состояния согласно ГОСТ 31937-2011 [2]. При уменьшении в процессе эксплуатации прочностных характеристик несущих конструкций динамические характеристики могут изменяться, и по степени их отклонения от нормы можно судить об изменении прочности сооружения.

Вместе с этим здания сами выступают в качестве источника сейсмических волн. В регистрируемых сейсмических сигналах обычно преобладают колебания первой формы (на основной частоте). Иногда обертоны также являются интенсивными - значения частот определяются конструктивной схемой сооружения [1]. В случае близкого расположения сейсмоприемников к таким источникам наличие в зарегистрированном сигнале помех может затруднять решение некоторых сейсмологических задач. Например, при сейсмическом микрорайонировании референсными методами (метод регистрации микросейсм/землетрясений/взрывов) сейсмическая опасность исследуемой территории может быть оценена не корректно [3]. 